\title{
Empirical Relationship between Secondary Education Investment in Zhejiang Province and Rural Economic Development
}

\author{
Liujie $^{1}$ Donglei Liu ${ }^{2}$ Yanhong $\mathrm{Ma}^{3}$ \\ ${ }^{1}$ Dept. of finance and management, Canvard College, Beijing Technology and Business University, Beijing, 100081, \\ China; \\ ${ }^{2}$ Business college, Agricultural University of Hebei, 071001, China \\ ${ }^{3}$ Dept. of finance and management, Canvard College, Beijing Technology and Business University, Beijing, 100081, \\ China;
}

\begin{abstract}
The work conducted an empirical research by linear econometrics and VAR models on the relationship between rural economic growth and secondary education investment in Zhejiang Province during the period from 1996 to 2012. Analytical methods were applied to the research, including unit root test, co-integration test and Granger causality. The results indicated a long-term stable relationship between rural economic growth and secondary education investment in Zhejiang Province.
\end{abstract}

Keywords: Education investment; Economic growth; VAR mode

\section{Introduction}

"Education is a fundamental task for the coming generation". Developing education is the fountainhead and engine of economic and social progress, as well as the improvement of people's living standard. By now, the free nine-year compulsory education project, covering almost nationwide, has achieved remarkable results. But the bad news is that under the binary structure of urban and rural, the rural-urban disparity has not been narrowed down yet. It has been widely considered that the secondary education has provided a multitude of manpower with relatively high quality for the rural society. Thus, it is worth paying attention by researchers and relevant policy makers on whether secondary education investment can serve as the engine of rural economic development.

Generally speaking, pedagogical economics, a discipline based on human capital theory, is generated owing to the formation of basic theoretical system of education investment. However, there is very little research aimed specially at rural secondary education. The early studies laid emphases at the macro level, mainly on the relation between overall education investment and macroeconomics, financial revenue and expenditure and education investment system. Less attention was paid to the distinction among elementary education, secondary education and higher education.

Since 2000, research on individual farm household has increased a great deal. There into, different views emerges on the question whether education investment is strikingly conducive to the economic growth. For instance, Yu Jingwen (2012) conducted a research on the relationship between economic growth and government education investment/ non-government investment. The results revealed that education investment(from government /non-government) had no marked effect on the economic development, whereas the education quality had a significant positive correlation with economic growth. Han Wenjing (2011) discovered an obvious input-output efficiency in the regional differences of input-output efficiency of government education investment. But different regions had various rates of contribution, of which the western part had the highest rate. In summary, from the perspective of macro economy, there is a deficiency in relational studies of secondary education investment and economic growth. While relational research on secondary education investment and rural economic development is still blank. Therefore, it is encouraged to explore the influence of rural secondary education investment on rural economic growth, which is both of realistic policy implications and of great help for the enrichment of related studies on pedagogical economics.

\section{Empirical analyses}

The work selected some relevant data of Zhejiang Province to carry out an empirical analysis of the relationship between secondary education investment and rural economic development. By linear econometrics and VAR modeling, the work verified whether there was a long-term stable relation between rural economic growth and secondary education investment in Zhejiang Province. Analytical methods were also utilized to aid in research, such as unit root test, co-integration test and Granger causality.

\subsection{Sample data}

Secondary education investment in Zhejiang Province (ZJT) mainly refers to the amount of secondary education expenditure in the whole province, including the sum total of expenditure in regular senior high school education and secondary professional education during the stage. There is no clear discrimination of rural economy and urban economy in the statistical 
yearbook, on account of the difficulty to obtain reliable evidence for the variable of rural economic development. Hence, gross farm production was selected in the work in place of rural economic growth indicators. Data from 1996 to 2012 was chosen as samples, all originated in China Educational Finance Statistics Yearbook (1996-2012) and China Statistical Yearbook (1996-2012).

\subsection{Model enactment and analysis}

\subsubsection{Unit root test}

Due to the mostly unstable economic statistics, direct modeling analysis may result in spurious regression. Before doing modeling analysis, it is required to test the stability of variable data. In view of dimensional differences, the first step is to conduct logarithmic processing of the data, and to adopt LN (NSZ) and LN Table 1 Results of unit root test on the variable

\begin{tabular}{llllll}
\hline variable & ADF test statistic & \multicolumn{2}{l}{ Test critical values: } & result \\
\cline { 2 - 5 } & & $1 \%$ & $5 \%$ & $10 \%$ & unstable \\
\hline LN( ZJT ) & -0.507160 & -3.920350 & -3.065585 & -2.673459 & unstable \\
L N ( NSZ ) & 5.258490 & -4.004425 & -3.098896 & -2.690439 & stable \\
D( L N (Z J T ) ) & -4.032868 & -3.959148 & -3.081002 & -2.681330 & stable \\
D ( L N ( NSZ ) ) & --8.200488 & -4.800080 & -3.791172 & -3.342253 & \\
\hline
\end{tabular}

\subsubsection{Long term equilibrium relationship analysis}

If the time series taken into account have the same co-integration order that decreases with a certain linear combination (co-integrated vector), there must be an obvious co-integration relation between these time series. The work thus utilized E-G two-step method to test the co-integration relation between $\mathrm{LN}(\mathrm{ZJT})$ and LN (NSZ). Firstly, the regression models of LN (ZJT) and LN (NSZ) established in use of least square method is shown as below:

$\mathrm{LN}(\mathrm{NSZ})=1.072120+0.383753 \mathrm{LN}$ (ZJT) (1)

It is found after data analysis that $\mathrm{R}^{2}$ equals 0.921581 and DW equals 1.552758. These two Tables are well fitted to the equation with the value of DW less than 2 . Table 2: Results of unit root test on the residual errors

\begin{tabular}{|c|c|c|c|c|c|c|}
\hline \multirow[t]{2}{*}{ variable } & \multirow[t]{2}{*}{$\mathrm{ADF}$} & \multirow[t]{2}{*}{ test statistic } & \multicolumn{3}{|c|}{ Test critical values: } & \multirow[t]{2}{*}{ result } \\
\hline & & & $1 \%$ & $5 \%$ & $10 \%$ & \\
\hline D (Error) & & -3.399100 & -3.959148 & -3.081002 & -2.681330 & stable \\
\hline
\end{tabular}

In addition, it is also revealed that the residual errors remain stable, inferring that there is a co-integration relation between LN (ZJT) and LN (NSZ). The fitting of data will turn out to be better particularly after adding a lagged variable of order 1 . Besides, it can also be seen that the two linear combinations has a long term stability after eliminating the autocorrelation of order 1 .

\subsubsection{Relational analysis of short term fluctuations}

In accordance with Granger theorem, if there is a co-integration relation between two variables, it is sure that the short time fluctuation relationship between them can be expressed by error correlation model (ECM). On this account, a corresponding error correlation model is built to respectively constitute the first lagged, second lagged and third lagged regression
(ZJT) as an expression of data after logarithmic processing. Then it is supposed to verify the unit root process of LN (NSZ) and LN (ZJT) by means of Eviews 7.2 software. As a result, the sequence of $\mathrm{LN}$ (NSZ) is found as an unstable time series with a unit root. After that, the author is required to take a first order differential of LN (NSZ) to convert into D (LN (NSZ)). If it passes the unit root test of stability, it will be verified that LN (NSZ) is integrated of order 1. In the same way, ADF test of LN (ZJT) proves unit root in the sequence of LN (ZJT) as an unstable time series. After logarithmic processing, it is confirmed that $\mathrm{LN}$ (ZJT) is also integrated of order 1, which explains that LN (NSZ) and LN (ZJT) are both uniformity integrated sequence possibly with a co-integration relationship as shown in Table 1.

Thus it can be concluded that the equation itself has an autocorrelation. Furthermore, appropriate lagged variables are added to the equation to resolve the problem of model's degree of fitting and autocorrelation. The regression equation is expressed as follows:

$\mathrm{LN}(\mathrm{NSZ})=0.602974+0.727840 \mathrm{LN}(\mathrm{NSZ})_{\mathrm{t}-1}+0.084806 \mathrm{LN}(\mathrm{ZJT})$ +4.30E-09 LN (ZJT) ${ }_{\mathrm{t}-1}(2)$

After revision, it turns out that $\mathrm{R}^{2}$ is equal to 0.984899 and DW is equal to 2.359327 , both well fitted to the equation without autocorrelation.

Then, Table 2 shows the results of unit root test on the residual errors of the equation with continuing application of Eviews 7.2 software.

models. With the application of OLS regression, the third lagged results are proved to be better than the previous two. Nevertheless, on the whole, the conspicuousness of each parameter still remains rather poor. From the third lagged regression, the results show that $\mathrm{R}^{2}$ equals to 0.703575 with non-distinctive test value $T$. It can be concluded that the rural economic growth can hardly be facilitated only by such an increase of secondary education investment in a short period of time. On the contrary, more investment in secondary education will give rise to a squeezing of other investments. Due to a long period and slow effectiveness of education investment, the benefits for rural economic development are not obvious. Considering that Zhejiang Province is economically developed, the agricultural GDP and agricultural population accounted for relatively low 
proportion ( $4.75 \%$ in $2013,36.8 \%$ in

2012 respectively), are below average national wide ( $10.1 \%$ and $64.71 \%$ respectively), secondary education effects on economical growth are more likely to transfer to non-agricultural industries.

\subsection{Granger causality}

It still needs further tests between variables by means of VAR model whether the equilibrium relation comprises Table 3: Test results of Granger causality

\begin{tabular}{lllll}
\hline hypothesis : & obs & Chi-sq & Prob. \\
\hline LN (ZJT) does not Granger Cause LN (NSZ) & 15 & 5.84487 & 0.0208 \\
LN (NSZ) does not Granger Cause LN (ZJT) & 15 & 1.48859 & 0.2717 \\
\hline
\end{tabular}

Through testing the stability of non-constraint vectors auto regression between LN (ZJT) and LN (NSZ), it is uncovered that VAR model is stable. For quite a long period of time, LN (ZJT) is the Granger causality of LN (NSZ), whereas LN (NSZ) is not the Granger causality of DLN (ZJT), In light of the testing results, the rural secondary education investment is the Granger causality of rural economic development, the increase of secondary education investment does make a certain contribution to the rural economic development in the long run.

2.4 Variance decomposition

Results of the model of LN (ZJT) and LN (NSZ)

variance decomposition are showed as Table 4: causal relationship. Based on AIC and SC rule, the results under the condition of lag phase 3 are shown as follows: Within a short time, LN (ZJT) is the Granger causality of LN (NSZ), whereas LN (NSZ) is not the Granger causality of LN (ZJT). The test results are displayed in Table 3.

Table 4: Variance decomposition tests

\begin{tabular}{llllllll}
\hline \multicolumn{2}{l}{ LN (NSZ) Variance decomposition } & \multicolumn{5}{c}{ LN (ZJT) } & Variance decomposition \\
\hline & & & & & & \\
Period & S.E. & LN (NSZ) & LN (NSZ) & Period & S.E. & LN (NSZ) & LN (NSZ) \\
\hline 1 & 0.034479 & 100.0000 & 0.000000 & 1 & 0.153564 & 11.98695 & 88.01305 \\
2 & 0.044243 & 99.93734 & 0.062658 & 2 & 0.217187 & 28.23893 & 71.76107 \\
3 & 0.057931 & 75.01633 & 24.98367 & 3 & 0.253546 & 29.38997 & 70.61003 \\
4 & 0.081842 & 53.84211 & 46.15789 & 4 & 0.302746 & 25.09201 & 74.90799 \\
5 & 0.103635 & 45.53847 & 54.46153 & 5 & 0.353375 & 22.98701 & 77.01299 \\
6 & 0.124800 & 38.50625 & 61.49375 & 6 & 0.393559 & 21.83842 & 78.16158 \\
7 & 0.146604 & 32.92829 & 67.07171 & 7 & 0.428695 & 20.38114 & 79.61886 \\
8 & 0.166704 & 29.26186 & 70.73814 & 8 & 0.460251 & 19.09471 & 80.90529 \\
9 & 0.184291 & 26.57663 & 73.42337 & 9 & 0.485826 & 18.14968 & 81.85032 \\
10 & 0.199669 & 24.43895 & 75.56105 & 10 & 0.505656 & 17.37223 & 82.62777 \\
\hline
\end{tabular}

\section{Conclusions}

After analyzing the empirical results of related data in Zhejiang Province, it is revealed that as a result of slow effectiveness of education, the secondary education investment in Zhejiang Province exerts a non-distinctive influence on the rural economic growth within a short time. But in the long run, there is a co-integration relation between them, namely the secondary education investment is the cause of rural economic growth. Such an influence also reflects a multi-phases superposition effect, which manifests that the function of education investment on economic development can never accomplish in an action. But with regard to the degree of contribution, all regression
LN(NSZ)contributes itself lower gradually. LN(ZJT)'s contributions to LN (NSZ) is lower in short term. But in the long term, the rate would increase gradually to $75 \%$. Whereas LN (NSZ) 'S contributions to LN (ZJT) is lower, both are below 20\%. LN (ZJT) contributes itself are stable, the rate is between $70 \%$ to $80 \%$.This conclusion verified the above results: the Correlation between the secondary education investment and the rural economic development is not significant in the short term. In the long term, the change of secondary education investment could explain the change of the rural economic development, the secondary education investment is the cause of rural economic growth.

coefficients are less than 1, indicating that the functional strength is still not sufficient enough to obtain improvement. Considering that Zhejiang Province is economically developed, the agricultural GDP and agricultural population accounted for relatively low, resulting that secondary education may have a spillover effects when contributing to non-agricultural industry growth.

\section{Acknowledgements}

Sincere thanks go to Beijing Municipal Education Commission for the financial subsidy to the project of China's Rural Secondary Education Investment: Macroscopic Performance and Microscopic Behavior. It is selected in the Beijing Non-government Funded 
Education Promotion Project-Youth Talent Plan-Canvard Institute of Beijing Technology and Business University.

\section{Reference}

[1] Chen Xia. "Coordinating Relations between Higher Education Investment and Economic Development", Doctoral dissertation in Xinjiang University, 2011. P87.

[2]Zheng Liqin. "Empirical Research on Higher Education Funding in Five Province of Northwestern-Based on Model of LMDI", Mathematics in Practice and Theory, 2014. 2: p92-93.

[3] Wang Xin \& Zhang Juan. "Empirical Research on Education Investment in Shanxi Province and Economic Growth", Journal of Shanxi Finance and Taxation College, 2010. 10: p65. 